This item was submitted to Loughborough's Research Repository by the author.

Items in Figshare are protected by copyright, with all rights reserved, unless otherwise indicated.

\title{
Conducting research with the disabled and disadvantaged
}

PLEASE CITE THE PUBLISHED VERSION

PUBLISHER

(C) Taylor \& Francis

LICENCE

CC BY-NC-ND 4.0

\section{REPOSITORY RECORD}

Hitchcock, David, Victoria Haines, and Susan Swain. 2019. "Conducting Research with the Disabled and Disadvantaged”. figshare. https://hdl.handle.net/2134/2361. 


\title{
CONDUCTING RESEARCH WITH THE DISABLED AND DISADVANTAGED
}

\author{
David Hitchcock ${ }^{1}$, Victoria Haines ${ }^{2}$ and Susan Swain ${ }^{1}$ \\ ${ }^{1} C E D S$ \\ The Acorn Centre \\ 51 High Street \\ Grimethorpe $S 727 B B$ \\ ${ }^{2}$ ESRI \\ Holywell Building \\ Holywell Way \\ Loughborough LE11 3UZ
}

\begin{abstract}
Based on their own project work, this paper presents a pragmatic and experience-based review of the advantages and difficulties of conducting research with and on behalf of those with disabilities or who are otherwise disadvantaged. It considers the financial aspects, health and wellbeing issues and the factors which should be considered in the preparation of proposals and the management of projects.
\end{abstract}

\section{Introduction}

The Centre for Employment and Disadvantage Studies (CEDS) is the research division of yes 2 work, a social firm working with those who have disabilities or are otherwise disadvantaged. Many of CEDS projects stem from the need to identify practical solutions to barriers faced by those seeking to attain and maintain employment. Other research commissions derive from a wider remit to increase the understanding of the factors which need to be considered by those responsible for the design of accessible activities, equipment and facilities. In both cases, CEDS research is founded on ergonomics principles for robust information collection and analysis.

The ergonomics approach demands an accurate analysis of the activities of concern, including the environment in which they are performed, and a thorough understanding of the humans involved. This presents a fundamental difficulty for CEDS and others similarly involved in conducting research with the disabled and disadvantaged - just what are their pertinent characteristics? In mainstream ergonomics projects, despite an increasing wealth of literature there often appears to be a lack of directly relevant data. Projects involving the disabled and disadvantaged typically have even less to draw upon; with a distinct lack of specific anthropometry and capabilities data. 
This article does not attempt to be definitive, and the authors recognise the excellent work of others in this area, but it seeks to draws on CEDS' experience, to promote discussion, particularly among the ergonomics community, as to how best serve and benefit from the non-mainstream population.

\section{A Matter of Understanding}

In common with all projects - irrespective of disability - the starting point needs to be to ensure that at the project negotiation stage, the client, the researcher and the beneficiaries (the users) are all clear and in agreement as to the aims, objectives, means and outcomes of the work.

\section{The Client}

In CEDS' experience most clients appear unsure as to precisely what they mean by the terms 'disability' and 'disadvantaged'. For example, it is not uncommon for clients to think of disability issues to be restricted only to the difficulties and needs of those in wheelchairs. In some instances, the client's concept of disability may also extend to the needs of the blind or even the hard of hearing. This is not intended to sound harsh or critical; it is simply a reflection on the realities of commission with a client having a specific objective. Without up-front direction from the researcher it seems that projects can set off 'on the wrong foot', ultimately leading to inaccurate outcomes. A project can begin with the best of intentions, aware of the parameters that have been set (e.g. evaluating a design only on the aspects of wheelchair access) but several months down the line when the report is published it is all too easy for the findings to be presented in such a way as to give the impression that all aspects of accessibility have been considered. The cynic might argue that this is the inevitable outcome of a client paying lip service to the needs of those with disabilities in order sell more product, or to prove a particular point. However, it is probably more likely to be a combination of misunderstanding of definitions, the passing of time, and the twists and turns which both pure and applied research projects can take.

Although clearly requiring redress, this limited view of disability is perhaps less troublesome than one which recognises a need to address all aspects of all disabilities and disadvantage. Where a client appreciates that disability and disadvantage address a wide array of issues and user needs, the project objectives may become fuzzy and the overall approach somewhat iterative. With so many factors to consider the project can be slow to define while all stakeholders debate and agree exactly what impairments should be given priority. In an ideal world it would be good to consider all disability types to be of equal importance. This, however, is rarely practical or necessary. Where inclusive design is the goal then the wider remit is essential, but for more targeted projects certain impairments are more relevant than others. Clarity is the key.

Before going further, it is worthwhile attempting to define the terms. The Disability Rights Commission (www.drc-gb.org) suggest that $20 \%$ of people of working age in the UK are considered by the government to be 'disabled' in that they have a disability or a long-term health condition that has an impact on their day to day lives. 
This includes people with cancer, diabetes, multiple sclerosis and heart conditions; people who have a hearing or sight impairment or a significant mobility difficulty, or who have mental health conditions or learning difficulties. It is this vast range of conditions which can often extend beyond the mindset of the client or researcher and, therefore, the project remit.

CEDS adopts a simple and common definition for 'disadvantaged', as being deprived of basic social rights and security through poverty, discrimination, or other unfavourable circumstances. While this embraces an even more diverse range of conditions, the client tends to focus on specific aspects such as alcoholism, drugs use, long-term unemployment, minority groups and the so on. As a result, there appears to be less confusion regarding projects aims and objectives. Of course, from the ergonomics perspective, the range of influential factors does not decrease, but in general they are less overt at the onset of the project. For simplicity, therefore, this article will focus on the disability matters, although the points raised may translate well to the issues of disadvantage.

\section{The Researcher}

The researcher can mirror the client's perspective of disability, and as such can present similarly undesirable constraints or otherwise to the research if they are not clear as to the project inclusions. Beyond this, in the authors' experience it is the expectations placed on the researcher which can cause difficulties. The ergonomics researcher is often viewed upon as an expert in disability rather than ergonomics. Their knowledge is unrealistically expected to extend to cover all kinds of disability by client and subject alike. This can lead to frustration from the client and all manner of communication obstacles with subjects. Under these circumstances, the researcher - and the project - may be made unnecessarily vulnerable and may be compromised.

\section{The Subjects}

Subjects should be made just as clear about the project purpose and objectives. Even though they may also be the beneficiaries this is not always straightforward. People are affected by disability or health conditions in different ways and the onset of disability varies. It could be from birth, due to an accident or a sudden incident such as a stroke or a gradual process. In other words, disability adds even more differences to what the ergonomist recognises as human variability.

Furthermore, and most importantly, the person is not defined by their disability or the researcher's view of them (Michailakis, 2003). Psychosocial factors are given increasing consideration in ergonomics studies so it should be of little surprise to find that while it might be convenient for the researcher to categorise each subject by their primary disability, it may be secondary disabilities or other issues which are more important to the subject. In conducting research into the usability issues of an inclusive pub, the authors discovered that disabled customers were as concerned about the "quality of the beer" and the "provision of condom machines" as they were accessible bars, tables and toilets. In another study looking at the successes and otherwise of people with various disabilities attaining and maintaining fulfilling employment; issues such as finance, organisational culture and inconvenient working hours were identified as influential factors alongside those specific to their disabilities. 


\section{A Matter of Planning}

\section{Representation}

User consultation is central to the ergonomics approach. Ensuring the representation of those participating in the research is fundamentally important. Convenience can be the compromise here. Using a simple example; perhaps the subjects need to be wheelchair users. In can be easiest to gather sufficient subjects from, for example, the local wheelchair basketball team who may be relatively young and fit and therefore not necessarily representative of the target user group.

Several agencies, including CEDS, maintain subject databases but the researcher must be aware that recruiting representative participants is complex and time-consuming for a variety of reasons; geographical spread, travel difficulties, lack of independence, communication constraints, fear of losing benefits through paid participation and ethical approval. This means that simultaneous multi-user activities such as focus groups are difficult to arrange. If project resources allow then the benefits of individual consultation can be achieved, particularly if the researcher can travel to the subject rather than the other way around. Familiarity of surroundings for the subject can create comfort and enable greater accuracy of response if, for example, the questions poised by the researcher are in context with the environment and activities.

\section{Working 'For' or Working 'With'}

It is well established that there are benefits from involving people with disabilities in research about them - motivation to participate (Joseph et al, 2005), improved quality of data (Osher et al, 2001) and greater understanding of actual user needs (Hitchcock and Taylor, 2003). Emancipatory research - where those studied make decisions about the research design and data analysis - offers an approach for true involvement (Good, 2001). CEDS endeavours to engage researchers with appropriate control whenever possible and have found that clients are particularly keen to see such involvement, but the practical problem for the ergonomist is the limited availability of disabled people within the discipline.

\section{Flexibility}

The adverse effects of medication, 'bad days' and external circumstances such as hospital appointments require a flexible approach to project planning. Participants may cancel at short notice and if an individual feels overloaded they may even need to pull out of the project altogether. Over reliance on any one individual in a relatively tight timeframe can be a mistake. However, careful and flexible planning can enable projects to run smoothly, particularly if milestones do not have to necessarily be sequential and different strands of the project can be run in parallel.

Unfortunately, if an inflexible approach is adopted and problems do arise, the inevitability may occur when researchers are left with little choice other than to make assumptions, rely on literature alone or try simulation in some way. At best these approaches can raise awareness and promote further questioning. They are not a substitute for user involvement. 


\section{A Matter of Perspective}

Probably one of the biggest challenges facing the ergonomics researcher is that of not making assumptions about their subjects. This is not unique to the disability arena, but is perhaps emphasised, not least because, as already mentioned, it may be unfairly assumed by the client or subject that the researcher is an expert in disability rather than ergonomics. It is possible that having been involved in the project or area for a while that even the researcher begins to assume this too! It should be remembered that there may be considerable perceived and actual differences in understanding and power between researchers and subjects (Bollard, 2003) which can make qualitative research problematic (Llewellyn, 1995), particularly for those with intellectual disability. Steps should be taken to ensure that all those involved in a project are working from a level playing field and that additional efforts and resources are provided where necessary; disability awareness training for researchers, providing assistants for those with memory loss, developing communication skills for those with speech or hearing impairments, using alternative formats for those with learning difficulties and so on.

\section{Concluding Thought}

Conducting research with the disabled and disadvantaged is far from straightforward but with clear objectives set by all those involved, methods devised with participants and a fluid timetable it is possible to generate realistic, accurate and beneficial outcomes.

\section{References}

Bollard, M., 2003, Going to the Doctor's: The Findings from a Focus Group with People with Learning Disabilities, Journal of Learning Disabilities; 7(2) 2003, 156-164

Disability Rights Commission, www.drc-gb.org

Good, G. A., 2001, Ethics in research with older, disabled individuals, International Journal of Rehabilitation Research; 24(3) 2001, 165-170

Hitchcock, D.R., Taylor A. J., (2003). Simulation for Inclusion - true user centred design? Include 2003 Conference Proceedings (The Helen Hamlyn Research Centre)

Joseph, D., Wailoo, M.P., Jackson, A., Petersen, S. A., and Anderson, E.S., Participation of disadvantaged parents in child care research, 2005, Child Care, Health and Development; 31(5) 2005, 581-587

Llewellyn, G., 1995, Qualitative research with people with intellectual disability, Occupation Therapy International; 2(2) 1995, 108-127

Osher, T. W., van-Kammen, W., and Zaro, S. M., 2001, Family participation in evaluating systems of care: Family, research, and service system perspectives, Journal of Emotional and Behavioral Disorders; 9(1) 2001, 63-70 